\title{
OS REFUGIADOS EM MANIFESTOS POLÍTICOS PRESIDENCIAIS: ENTRE SILENCIAR E DAR VOZ
}

\author{
Alexandra Guedes Pinto \\ Departamento de Estudos Portugueses e Estudos Românicos, Faculdade de Letras, Universidade do Porto, Portugal
}

\begin{abstract}
Resumo
A crise dos migrantes e refugiados na Europa do século XXI originou novas divergências no velho continente que colocam desafios difíceis à construção da identidade europeia. Classificada já como a maior crise migratória e humanitária do pós-guerra, a realidade dos migrantes e refugiados revelou uma Europa incapaz de responder ao problema com uma solução conjunta. Para além do aspeto humanitário, muitas vezes de contornos dramáticos explorados pelos média, o fenómeno é também motivo de fricções entre as instituições e os Estados-membro da União Europeia, ameaçando tornar-se o gatilho de uma crise política e de um novo equilíbrio de forças entre os Estados. Dada a centralidade que ganhou, a crise dos refugiados pode também ser perspetivada do ponto de vista do aproveitamento político por parte de diferentes fações, que dela extraem dividendos importantes para a sua própria territorialização. Discursos europeístas, de tolerância e aceitação, baseados nos ideais solidários do projeto europeu, coexistem com discursos extremistas, de tendência xenófoba e anti-integração. Na presente reflexão, analisamos a forma como o discurso político eleitoralista, do género textual manifesto político, codifica argumentativamente a questão dos refugiados, focalizando, para esse efeito, quatro dos manifestos eleitorais dos candidatos às eleições presidenciais portuguesas de 2016. A partir da caracterização do género seguindo a proposta de Adam (2001, pp. 40-41) das componentes semântica, composicional/estrutural, enunciativa, pragmática, estilística e fraseológica, metatextual, peritextual e material, confirmamos que existe, simultaneamente, unidade e diversidade nos exemplares analisados. Por um lado, uma unidade que permite reconhecer nos diferentes textos manifestações de um mesmo género; por outro lado, uma diversidade que traduz/produz efeitos na construção do ethos e nas estratégias discursivas e políticas de cada candidato. $O$ tratamento da crise dos refugiados é justamente um dos temas cujo tratamento diverge substancialmente de manifesto para manifesto, revelando estratégias discursivas e políticas específicas.
\end{abstract}

Palavras-Chave

crise dos refugiados; manifestos políticos; género de texto; construção do ethos; estratégias discursivas e políticas

\section{REFUGEES IN PRESIDENTIAL POLITICAL MANIFESTOS: BETWEEN SILENCING AND GIVING A VOICE}

\begin{abstract}
The crisis of migrants and refugees in 21st century Europe has created new disagreements on the old continent that pose difficult challenges for the construction of European identity. Already classified as the most massive post-war humanitarian and migratory crisis, the reality of migrants and refugees has revealed a Europe unable to respond to the problem with a joint solution. In addition to the humanitarian aspect, often of dramatic contours exploited by the media,
\end{abstract}


the phenomenon is also a source of friction between the institutions and the Member states of EU, threatening to become the trigger for a European political crisis and a new balance of forces between States. Given the centrality it has gained, the refugee crisis may also be viewed as a means of pursuing strategic advantage by different political factions, which extract significant dividends for their territorialisation from the issue. Europeanist discourses of tolerance and acceptance, based on the ideals of solidarity of the European project, coexist with extremist, xenophobic and anti-integration discourses. In the present reflection, we analyse how the electoral political discourse, of the textual genre political manifesto, encodes argumentatively the refugee question, focusing, for this purpose, four of the electoral manifestos of the candidates for the Portuguese presidential elections of 2016. Following the proposal of Adam (2001, pp. 40-41) for the characterisation of a genre (in semantic, compositional/structural, enunciative, pragmatic, stylistic and phraseological, metatextual, peritextual and material components), we confirm that there is unity and diversity in the analysed specimens. On the one hand, unity that enables recognising the different texts as manifestations of the same genre; on the other hand, diversity that translates/produces effects in the ethè and discursive/political strategies of each candidate. The refugee crisis is precisely one of the topics whose management diverges substantially from manifesto to manifesto, revealing specific discursive and political strategies.

\section{KEYWORDS}

refugees crisis; political manifestos; textual genre; ethos construction; discursive and political strategies

\section{INTRODUÇÃO}

A crise dos migrantes e refugiados na Europa do início do século XXI abriu as portas a novas divergências no velho continente que colocam desafios difíceis à construção da identidade europeia.

Classificada já como a maior crise migratória e humanitária na Europa após a Segunda Guerra Mundial, a realidade dos migrantes e refugiados pôs a nu uma Europa incapaz de responder ao problema com uma solução única e conjunta. Para além do aspeto humanitário, muitas vezes de contornos dramáticos explorados pelos média, o fenómeno é também motivo de fricções e fissuras entre as instituições e os Estados-membro da União Europeia, ameaçando tornar-se o gatilho de uma crise política europeia, conducente a um novo equilíbrio de forças entre os Estados.

Dada a centralidade que ganhou, a crise dos refugiados pode também ser perspetivada do ponto de vista do aproveitamento político por parte de diferentes fações, que dela extraem dividendos importantes para a sua própria territorialização. Discursos europeístas, de tolerância e aceitação, baseados nos ideais solidários do projeto europeu, coexistem com discursos extremistas, de tendência xenófoba e anti-integração.

$\mathrm{Na}$ presente reflexão, analisaremos a forma como o discurso político eleitoralista, do género textual manifesto político eleitoral, codifica argumentativamente a questão dos refugiados, focalizando, para esse efeito, os manifestos eleitorais dos candidatos às eleições presidenciais portuguesas de 2016 '.

\footnotetext{
' Note-se que, apesar da distância temporal entre a data dos manifestos em análise e a data de publicação deste trabalho, estamos a falar da análise das mais recentes eleições presidenciais portuguesas e aquelas que aconteceram no auge da crise dos refugiados.
} 


\section{Contextualização}

Começando por uma brevíssima contextualização histórica dos discursos em análise, lembramos que as eleições presidenciais em estudo foram as nonas eleições para a Presidência da República Portuguesa, desde a Revolução de 25 de abril de 1974, que repôs o regime democrático constitucional em Portugal. Tiveram lugar em 24 de janeiro de 2016 e decidiram o sucessor do presidente à data, Aníbal Cavaco Silva.

Dos 10 candidatos a concurso nestas eleições, apenas cinco disputaram mais diretamente o acesso ao cargo, a saber: Marcelo Rebelo de Sousa, António Sampaio da Nóvoa, Marisa Matias, Maria de Belém Roseira e Edgar Silva, visto que os restantes obtiveram votações menos expressivas.

Entre os mais votados, destacaram-se Marcelo Rebelo de Sousa, que acabou por vencer com maioria absoluta, obtendo $52 \%$ dos votos, e António Sampaio da Nóvoa, que ficou em $2 .^{\circ}$ lugar, com cerca de $23 \%$ dos votos. Estes dois candidatos mais votados propuseram-se, inicialmente, como independentes, mas acabaram por conseguir o apoio de dois dos principais partidos políticos portugueses, designados como os partidos do "Bloco Central" (PSD e PS, respetivamente). Os outros três candidatos mais votados foram Marisa Matias, representante do Bloco de Esquerda, que contou com $10 \%$ dos votos; Maria de Belém Roseira, militante socialista, mas a concorrer como independente, com 4,24\% da votação; e o candidato comunista, Edgar Silva, que obteve $3,95 \%$ dos votos ${ }^{2}$.

Apesar de, no momento das eleições em causa, Portugal não estar já sob a supervisão do programa de assistência financeira da Troika ${ }^{3}$, o país enfrentava ainda os efeitos de uma crise económica e social profunda, com difíceis metas a cumprir junto dos credores e algumas medidas de austeridade muito sensíveis, que marcaram de forma indelével o contexto deste plebiscito. A quase totalidade dos manifestos analisados reflete o seu contexto de produção, nomeadamente através da denúncia forte do estado do país; da expressão do descontentamento e revolta face ao estado de coisas vigente; do ataque aos atores sociais considerados responsáveis pela situação e através de propostas várias de superação e mudança.

\section{TIPO DE DISCURSO E GÉNERO DE TEXTO}

Um outro aspeto relevante na caracterização destes discursos é a sua inclusão no género de texto e no tipo de discurso respetivo.

Utilizando a proposta de Adam (2001, pp. 40-41) para a delimitação de géneros textuais, segundo as componentes semântica, composicional/estrutural, enunciativa, pragmática, estilística e fraseológica, metatextual, peritextual e material, esboçamos

\footnotetext{
${ }^{2}$ Os resultados eleitorais foram consultados na página: https://www.eleicoes.mai.gov.pt/presidenciais2016/resultados-globais.html

3 "Troika", neste contexto de uso, foi um termo popularizado durante a crise da zona euro para descrever o grupo formado pela Comissão Europeia, o Fundo Monetário Internacional e o Banco Central Europeu como o grupo de credores que impôs medidas de austeridade a estados europeus endividados - como a Irlanda, Portugal, Chipre e Grécia - em troca dos resgates financeiros providenciados.
} 
aqui uma caracterização breve deste género de texto manifesto político eleitoral dentro do tipo de discurso político 4 .

Um manifesto eleitoral é um documento em que um candidato ou um partido identificam as suas posições e estratégias políticas e definem as suas propostas de ação e de legislação futura, no caso de conquistarem votos suficientes para chegarem ao poder. Trata-se de uma declaração pública de princípios e intenções, destinada a mobilizar uma comunidade na adesão a um projeto político, tendo, por isso, propósitos pragmáticos estáveis que são os de confirmar as posições políticas do locutor, comprometê-lo com a execução futura de determinadas ações, e apelar à adesão do destinatário.

Do ponto de vista composicional, o manifesto possui dimensões variáveis e uma estrutura relativamente livre, mas com algumas componentes regulares. Compreende sempre uma sequência de abertura com um título destacado graficamente ${ }^{5}$, que identifica um eixo semântico-pragmático central da proposta do candidato, o "mote da campanha", seguido de um ou vários atos de saudação do tu, podendo também ocorrer atos expressivos de agradecimento; compreende também uma sequência de fecho, com atos diretivos de incitação ao voto e o encerramento, com a identificação do local, da data, e da(s) assinatura(s) dos autor(es), à semelhança do que se passa com uma carta ${ }^{6}$. A sequência de desenvolvimento está sempre dividida em macroestruturas identificadas através de subtítulos. Estas subdivisões correspondem à identificação das principais secções semântico-pragmáticas do texto, que variam de caso para caso, mas que incluem sempre duas grandes partes: a parte em que o candidato caracteriza o contexto vigente e a parte em que o candidato formula os princípios defendidos e as propostas de ação futura. As sequências textuais dominantes, tendo em conta a proposta das sequências textuais de Adam (2008), são, prototipicamente, a expositiva e a argumentativa.

Os manifestos eleitorais presidenciais têm marcas do seu enunciador à superfície do discurso, quer seja através do eu, quer seja através do nós (não inclusivo e inclusivo)7, sendo formulados por locutores que se declaram, através do seu manifesto, como atores políticos, mudando, desta forma, o seu estatuto de cidadãos comuns para o de candidatos presidenciais ${ }^{8}$. No quadro desta afirmação do $e u$, torna-se particularmente relevante a construção do ethos do locutor, que se faz, prototipicamente, pelo menos parcialmente, por alteridade, ou seja, por oposição a um outro de que o eu se serve para se autoidentificar e face a quem se posiciona para construir uma identidade qualificada. Neste contexto, surgem enunciados de polarização de um eu/nós face a um eles/os outros que o locutor critica e de quem se distancia.

\footnotetext{
4 É possível consultar uma caracterização do género manifesto presidencial segundo a proposta de Adam (2001) em Pinto, Pinho e Teixeira (2017). É possível, ainda, rever algumas das características deste género em Pinto (2012).

5 O título é normalmente acompanhado de uma imagem do(a) candidato(a), no caso dos manifestos eleitorais presidenciais.

${ }^{6}$ A classificação dos atos ilocutórios dominantes nos manifestos políticos em estudo segue o modelo de Searle (1969).

7 Já Benveniste (1966) afirmava que o nós é uma junção entre o eu e o não-eu. Este não-eu pode ser o tu ou o eles, distinguindo-se a forma inclusiva $(e u+t u)$, que inclui o interlocutor, da forma exclusiva $(e u+e l e s)$, de que o interlocutor é excluído. As ocorrências do nós nos manifestos presidenciais em análise distribuem-se em ocorrências do nós inclusivo, em que se fundem o eu e o tu, e ocorrências do nós não inclusivo, em que o nós implica eu + os outros, "outros membros do partido que represento" ou "outros apoiantes da minha candidatura".
}

${ }^{8}$ Ver Pinto, Pinho e Teixeira (2017, p. 39). 
Em termos linguísticos, a superfície destes discursos contém marcas fortes de modalização e subjetividade, traços relacionados com a presença do locutor no seu texto e também marcas fortes de argumentação, que suportam a presença da controvérsia e da persuasão.

Do ponto de vista metatextual, estes documentos são normalmente identificados pelos seus autores como "manifestos", havendo, todavia, algumas variações nestas referências metatextuais, tais como as que acontecem no caso em estudo, em que António Sampaio da Nóvoa renomeia o seu manifesto, chamando-lhe "Carta de princípios"9, Edgar Silva, que intitula o seu como "Declaração de candidatura" Rebelo de Sousa", que não identifica o seu texto com qualquer rótulo metatextual'2.

Ainda, dos pontos de vista peritextual e material, acrescentaremos sumariamente que estes textos circulam tanto como textos impressos, por vezes distribuídos nas sessões de apresentação pública das candidaturas em que são comunicados oralmente, como enquanto textos digitais, normalmente colocados no website das candidaturas e, por vezes, nas próprias páginas dos partidos apoiantes. Tanto nas páginas impressas como nas páginas digitais, os textos estabelecem fronteira com outros textos, como sejam as fotografias dos candidatos, a identificação dos links das páginas das candidaturas, entre outros. A dimensão dos manifestos, no caso em apreço, varia entre uma versão mais curta, de que é exemplo o manifesto de Marcelo Rebelo de Sousa, com 1.400 palavras, até uma versão mais longa, de que é exemplo o manifesto de Edgar Silva, com 3.929 palavras.

\section{OS MANIFESTOS PRESIDENCIAIS DE 2016}

Torna-se claro, a partir do exposto na secção anterior, que, entre os manifestos analisados, se desenha uma área de prototipicidade, com a saliência de alguns aspetos regulares e partilhados, aos níveis previstos por Adam para o recorte de um género (2001), aspetos esses que nos habilitam a falar do desenho de um género de texto específico, dentro do tipo de discurso político: o manifesto político eleitoral.

Em contrapartida, embora o enquadramento num género de texto nos permita antecipar algumas linhas de organização comuns dos manifestos, a verdade é que se percebe também, em cada um deles, uma área de especificidade, com diferenças semântico-pragmáticas, estilísticas e enunciativas, que são resultado e, simultaneamente, que produzem efeitos da/na construção do ethos e das/nas estratégias discursivas e políticas de cada um. A abordagem do tópico dos refugiados/migrantes é justamente um dos aspetos em que os manifestos presidenciais em estudo se revelam diferentes ${ }^{13}$.

\footnotetext{
${ }_{9}$ Informação disponível em http://www.sampaiodanovoa.pt/principios/

10 Informação disponível em https://edgarsilva2016.pt/declaracao

"Informação disponível em https://www.juntosporportugal.pt/

${ }^{12}$ Note-se, ainda, que a declaração oficial de Marisa Matias, identificada como "manifesto" se encontrava disponível na página oficial da sua candidatura às presidenciais de 2016, no link: http://marisa2016.net/candidata/manifesto.html. Esta página deixou, entretanto, de estar acessível, podendo a declaração ser confrontada em versão audiovisual (EsquerdaNet, 2015).

${ }_{13}$ Para este trabalho foram confrontados os cinco manifestos eleitorais presidenciais das eleições de 2016 dos candidatos
} 


\section{VENHO DE UMA FAMÍLIA DE EMIGRANTES: O ETHOS EMPÁTICO NO MANIFESTO DE MARCELO Rebelo de Sousa}

De entre os quatro manifestos confrontados, o manifesto de Marcelo Rebelo de Sousa é o que se afirma como o menos prototípico.

Este candidato, que partia nas sondagens já com uma larga vantagem e que acabou por ganhar as eleições, era Professor Catedrático na Faculdade de Direito da Universidade de Lisboa e possuía já uma longa carreira política, tendo assumido vários ministérios em Governos constitucionais sucessivos. O candidato colaborou também, como comentador político, na rádio e em dois canais de televisão generalistas, tendo adquirido, graças a esta exposição, uma influência mediática grande. Terá sido, porventura, esta vantagem mediática que lhe permitiu a construção de uma estratégia discursiva atípica.

Com efeito, se, de uma forma geral, os manifestos políticos se caracterizam por uma construção discursiva fundamentada num processo de polarização do eu face ao outro ("Apresentação positiva do eu e negativa do outro", Wodak, 2001, p. 73), criando dois eixos axiológicos antagónicos, resumíveis em: eu = bem versus o outro = mal, o manifesto presidencial de Marcelo Rebelo de Sousa afasta-se desta organização semântica e enunciativa, na medida em que o seu discurso se centra na caracterização do eu, através de uma exposição e uma argumentação que evidenciam o seu percurso de vida, os seus sucessos profissionais e pessoais, os cargos no setor público e privado, bem como alguns compromissos futuros muito genéricos, sem recurso à desqualificação do outro para se autoafirmar.

Veja-se, a título de exemplo desta estratégia não prototípica, o excerto seguinte, em que o candidato enaltece os candidatos oponentes: "ponderado tudo isto assim como as candidaturas anunciadas, todas elas a merecerem a minha maior consideração, e ponderada também a situação nacional à saída das eleições para a Assembleia da República tinha de fazer uma escolha" (Manifesto MRS ${ }^{14}$ ).

O manifesto de Marcelo Rebelo de Sousa é, também, o manifesto menos programático de todos, na medida em que o candidato não toma posição clara em relação a praticamente nenhum dos tópicos abordados pelos outros candidatos. O seu manifesto aposta, essencialmente, na construção explícita da imagem do eu, numa espécie de autobiografia, em que o proponente seleciona aqueles aspetos da sua identidade e da sua história de vida que lhe parecem mais relevantes para se autocaracterizar e para construir uma relação com o tu. É através da narração do seu percurso biográfico, que assume, por vezes, um tom confessional, de grande proximidade para com o tu, que a sua identidade pública se afirma como experiente, fiável, empática, solidária e digna do cargo de Presidente da República.

O político apenas indiretamente toma posição em relação ao tema sensível dos migrantes, fazendo-o mais uma vez num contexto de relato autobiográfico, ou seja,

\footnotetext{
mais votados. Neste processo, confirmamos que o manifesto de Maria de Belém Roseira não continha nenhuma menção explícita ou implícita à questão dos emigrantes, migrantes ou refugiados, motivo pelo qual não o consideramos para este estudo, que se focou nos restantes quatro manifestos presidenciais, a saber: os de Marcelo Rebelo de Sousa, António Sampaio da Nóvoa, Marisa Matias e Edgar Silva.

${ }^{14}$ Doravante, referiremos os excertos retirados dos manifestos em estudo através das iniciais dos seus proponentes. MRS corresponde, então, a Marcelo Rebelo de Sousa.
} 
mostrando que, sendo proveniente de uma família de emigrantes, ninguém mais do que ele conhece esta realidade e a aceita como estrutural na nossa sociedade. É, pois, num contexto não programático, mas sim de relato autobiográfico confessional, afetivo, que Marcelo Rebelo de Sousa insinua a sua posição de tolerância e aceitação relativamente a este assunto, ensaiando uma estratégia de aproximação do tu.

Veja-se a passagem abaixo, em que o candidato caracteriza a sua família como uma família de emigrantes:

sou pai de dois filhos e avô de cinco netos. A maior parte desta minha família vive no Brasil dando continuidade a uma gesta que o meu avô, os meus pais e um dos meus irmãos corporizaram como emigrantes. Sei, como um sem número de portugueses, o que custa a distância e o que vale sermos uma pátria dispersa pelo mundo em que muitos dos nossos melhores tiveram de partir porque não encontravam entre nós condições para ficar. (Manifesto MRS)

O manifesto de Marcelo Rebelo de Sousa é um manifesto constituído maioritariamente por atos assertivos, sendo quase inexistentes os atos diretivos, onde poderiam estar expressas recomendações ou apelos, e os atos compromissivos, contribuindo, isto, para a ausência de um ethos autoritário. Um dos poucos atos compromissivos executados pelo enunciador neste manifesto é o que encerra o seu discurso e que transcrevemos abaixo:

foi para dizer que cumprirei o meu dever moral de pagar a Portugal o que Portugal me deu que aqui vim e aqui estou. Serei candidato à presidência da república de Portugal, pelas portuguesas e pelos portugueses. (Manifesto MRS)

A escassez deste tipo de ato ilocutório, característico do discurso político e dos manifestos eleitorais, devido à formulação das chamadas "promessas políticas", marca também a diferenciação de posicionamento deste candidato. Cognominado posteriormente de "presidente dos afetos", poderíamos resumir o lema da sua candidatura como "eu sou um de vós", na medida em que esta estratégia de empatia é a estratégia mais poderosa que utiliza para se afirmar.

\section{O REGRESSO AOS IDEAIS DE SOLIDARIEDADE E PAZ DA EUROPA: O DISCURSO GENÉRICO Sobre os Migrantes no manifesto de António Sampaio da Nóvoa}

Professor Catedrático no Instituto de Educação da Universidade de Lisboa, onde ocupou já o cargo de reitor, Sampaio da Nóvoa candidatou-se às eleições presidenciais de 2016 como independente, embora tenha tido apoios à esquerda, de várias formações políticas e de ex-presidentes da República, tais como Mário Soares, Jorge Sampaio e Ramalho Eanes.

O manifesto de Sampaio da Nóvoa possui um conteúdo programático mais claro do que o de Marcelo Rebelo de Sousa, que se revela nas frequentes construções compromissivas do texto, exemplificadas através dos segmentos seguintes: 
defenderei o pluralismo, a diversidade, a discussão aberta dos problemas nacionais. (...) Lutarei contra o amorfismo, a indiferença, a resignação, a passividade, o conformismo e o pensamento único. (...) Não serei um Presidente passivo. (...) Usarei a palavra, a intervenção e a magistratura de influência de que o Presidente, e só o Presidente, dispõe. (Manifesto ASN)

Já os atos diretivos estão presentes em vários momentos deste discurso, sendo expressos por estruturas linguísticas diversificadas, mas todas com a presença da modalidade deôntica ${ }^{15}$, ora positiva, ora negativa, como podemos verificar nos exemplos seguintes:

esta é, tem de ser, novamente, a nossa hora (...). Não podemos aceitar que sejam postas em causa expectativas de quem trabalhou uma vida inteira. (...) Não podemos colocar portugueses contra portugueses, quebrar os laços solidários que devem unir as gerações. (...) Não podemos aceitar a vergonha do desemprego jovem e do trabalho precário, que são factores permanentes de corrosão, crimes contra a dignidade de cada um e o futuro de todos. (Manifesto ASN)

Em alguns destes atos, a modalidade deôntica cruza-se com a modalidade apreciativa da crítica, produzindo atos híbridos. Todavia, a crítica não surge de forma explícita e a construção do eu por oposição a um outro apenas fica disponível nestas sequências em que o candidato, identificando a instrução através da estrutura deôntica negativa não podemos $x$, acaba por verbalizar um conjunto de situações negativas no passado/ presente, das quais se demarca, apontando para as mudanças que se propõe executar.

O único momento em que o candidato faz uma alusão mais direta ao problema da emigração é no excerto seguinte:

as tensões dos últimos anos têm colocado em causa a coesão política da Europa e exigem um debate urgente sobre a democratização da União. (...) As alternativas estão, em grande parte, no regresso aos ideais europeus de solidariedade, de paz e de convergência, ideais pelos quais um Presidente da República tem de se bater, corajosamente. (Manifesto ASN)

Através deste exemplo, confirmamos que não existe, neste discurso, uma referência explícita ao tema dos migrantes ou refugiados, ao contrário do que veremos acontecer nos manifestos dos candidatos de esquerda, Marisa Matias e Edgar Silva, mas sim o enquadramento do tema numa questão mais geral, que é a da relação de Portugal com a Europa e o regresso da Europa aos seus ideais originais de solidariedade, paz e convergência. Esta tomada de posição, moderada, faz-se através da generalização e abstração do tema para o plano dos valores e ideais e serve para preservar a face positiva do candidato, que não se expõe em demasia, no que diz respeito a um assunto sensível e fraturante.

\footnotetext{
15 Apoiamo-nos, neste trabalho, em contributos anteriores para o estudo da modalidade em Linguística, tais como os de Oliveira $(2003,2013)$ e os de Campos (1991, 2004).
} 


\section{OS TERRÍvEIS FLAGELOS DOS REFUGIADOS: A HIPERBOLIZAÇÃo NO MANIFESTO DE EDGAR SILVA}

Edgar Silva, natural do Funchal, licenciou-se em Teologia e exerceu funções de Padre Católico. Em 1996, tornou-se deputado na Assembleia Legislativa da Região Autónoma da Madeira e, desde 1998, membro do Comité Central do PCP, renunciando à sua carreira religiosa. No manifesto que assinala a sua candidatura à Presidência da República, Edgar Silva constrói um ethos que assenta, sobretudo, no sentido de dever e de missão para com os portugueses.

Atualizando uma construção semântico-argumentativa mais prototípica dos manifestos políticos, a que aludimos na secção dois acima, a construção da imagem do eu na declaração de candidatura de Edgar Silva é feita em confronto com a imagem do outro. Para tal, o autor serve-se de estruturas linguísticas tais como estruturas deônticas positivas e negativas e de um léxico com dimensão axiológica marcada.

Para além destas sequências em torno de atos assertivos avaliativos, de atos expressivos, de crítica e de elogio, e de atos diretivos de recomendação, encontramos, no seu discurso, longas listas de atos compromissivos, performativos explícitos e não explícitos, onde o candidato apresenta o seu programa, que podemos ilustrar a partir dos exemplos seguintes:

comprometo-me com a causa da libertação das amarras da pobreza, encarando-a como dever do Presidente da República (...). Comprometo-me, entre outros objectivos, a promover a participação cívica e política e o diálogo com as estruturas representativas da Diáspora (...). Assumo e assumirei o compromisso da opção preferencial pelos mais pobres, pelos explorados.

(...) É um compromisso que tem orientado toda a minha vida. (...) Como candidato ou como Presidente da República defenderei, intransigentemente, os ideais libertadores de Abril. (Manifesto ES)

A imagem do eu/nós (os apoiantes e os potenciais apoiantes ${ }^{16}$ ) é construída através de um léxico eufórico que visa valorizar a face do locutor e do movimento político e cívico que este representa. Em oposição, a construção do outro é feita através de expressões lexicais com valor semântico avaliativo negativo ${ }^{17}$. Além da utilização do léxico disfórico, a imagem do outro é, também, construída através do uso da modalidade deôntica negativa em construções do tipo de não podemos $x$, que já vimos ocorrer no Manifesto de António Sampaio da Nóvoa:

não podemos ser cúmplices do ataque ao Serviço Nacional de Saúde e à Escola Pública. (...) Não podemos pactuar com o corte nas prestações

\footnotetext{
${ }^{16} \mathrm{O}$ nós inclusivo surge no manifesto como forma de construção de um ethos em que as fronteiras entre o eu e o tu se esbatem, configurando um ethos de pertença a uma coletividade: "assim, esta é a nossa candidatura, a nossa, de uma extensa e funda energia transformadora. Esta é, e será, a nossa candidatura a Presidente da República, a nossa, de um amplo movimento vital" (Manifesto ES).

${ }^{17}$ Veja-se, a título de exemplo, os excertos: "este é um tempo em que, em Portugal, depois de décadas de governação em confronto com os valores de Abril, se aprofundam as injustiças sociais e a exploração"; "multiplica-se a degradação social. Acentuam-se as chagas ambientais e agravam-se os problemas dos trabalhadores e alastra a pobreza, tudo na decorrência directa do domínio absoluto dos grandes grupos económicos" (Manifesto ES).
} 
sociais, com o roubo aos rendimentos, com a brutal injustiça fiscal, com o desemprego, a precariedade, a violação de direitos, enquanto se refina a proteção e apoio ao grande capital, que não pára de aumentar os seus colossais lucros. (Manifesto ES)

Através destas estruturas deônticas negativas, o locutor afirma uma posição crítica (sua e do movimento que representa), contrária a uma outra posição, identificada no complemento das orações em causa, onde são enumerados estados de coisas disfóricos, já referidos acima ("o ataque ao Serviço Nacional de Saúde e à Escola Pública"; "o corte nas prestações sociais", "o roubo aos rendimentos", "a brutal injustiça fiscal”, "o desemprego", "a precariedade", "a violação de direitos"). O locutor desqualifica, assim, a imagem de um outro, responsável pelos estados de coisas descritos e afasta-se deste, recusando-se a seguir políticas do passado e comprometendo-se a fazer de forma diferente:

esta candidatura que assumo exprime essa exigência de uma profunda ruptura e de viragem em relação às orientações políticas que tanta desordem e tanta regressão impuseram ao nosso País (...). Defendo que um outro Portugal é possível. Com uma economia mista que defenda os recursos e a produção nacional, o emprego, que promova a ciência e a tecnologia, que desenvolva e modernize as capacidades produtivas nacionais, que desenvolva a economia do mar e apoie os pescadores, apoie e incentive as micro, pequenas e médias empresas. (Manifesto ES)

Em passagens como a anterior, a argumentação é apoiada pelo uso do presente do conjuntivo que remete para um mundo potencial, diferente do mundo atual, que o candidato critica, configurando, numa mesma unidade, um complexo ilocutório de crítica sobre o passado / presente e de proposta para o futuro. As duas realidades passado + presente versus futuro são alvo de posicionamentos axiológicos antagónicos, sendo a primeira perspetivada como altamente negativa e a segunda, apresentada como altamente positiva, numa configuração polarizada do real ${ }^{18}$.

A construção de uma imagem negativa do outro ajuda a construção da imagem positiva do eu. As sequências em que o candidato desqualifica o outro são sequências de crítica com força ilocutória expressiva forte, tal como fica patente nos exemplos abaixo:

nos nossos dias, o País está a ser saqueado e destruído pelos especuladores, e os responsáveis pela governação decretaram a subordinação de Portugal aos mercados (...). As políticas dos últimos anos agravaram ainda mais as desigualdades sociais e a pobreza. Um modelo económico assente em baixos salários e em baixos níveis de qualificação, a crescente desresponsabilização do Estado das suas funções sociais, o forte agravamento do desemprego, a contenção dos rendimentos, os cortes nas pensões. (Manifesto ES)

\footnotetext{
${ }_{18}$ Para consultar uma análise completa das estratégias discursivas no Manifesto Presidencial de Edgar Silva às eleições presidenciais portuguesas de 2016, conferir Pinto, Pinho e Teixeira (2017, pp. 35-68).
} 
A referência ao fenómeno das migrações surge, justamente, numa destas sequências de crítica e denúncia, que transcrevemos abaixo:

este é um tempo em que, no Mundo, cresce uma perversa desigualdade económica entre os indivíduos e entre os países. Multiplica-se a degradação social. Acentuam-se as chagas ambientais e agravam-se os problemas dos trabalhadores e alastra a pobreza, tudo na decorrência directa do domínio absoluto dos grandes grupos económicos. Deste modo, degrada-se a injusta ordem internacional assente na despótica lógica dos mercados que, por cima dos Povos e dos Estados, se vai apropriando de todas as decisões e escolhas, multiplicando focos de tensão e de guerra, espalhando os terríveis flagelos das migrações forçadas e dos refugiados, do desemprego, da fome e da miséria, que mergulham grande parte da Humanidade em indizíveis carências e intoleráveis sofrimentos (...). Este é um rumo inaceitável. (Manifesto ES)

É, pois, numa longa sequência de censura, materializada em nomes semanticamente marcados por uma valoração negativa (desigualdade, degradação, problemas, chagas, tensão, guerra, flagelos, desemprego, fome, miséria, carências, sofrimentos); por adjetivos valorativos (alguns modais) altamente disfóricos (perversa, injusta, despótica, terríveis, forçadas, indizíveis, intoleráveis, inaceitável) e por paralelismos sintáticos de valor retórico (cresce $x$, multiplica-se $x$, acentuam-se $x$, agravam-se $x$, alastra $x$ ) que Edgar Silva refere a crise dos refugiados, mostrando que esta decorre da mesma fonte que origina os outros flagelos sociais (desemprego, fome, miséria...), contra os quais o candidato e o partido que o apoia tradicionalmente lutam. A fonte é "o domínio absoluto dos grandes grupos económicos" e a "despótica lógica dos mercados que impõe uma ordem internacional injusta e inaceitável". A tomada de posição é clara, com muitas marcas de subjetividade do eu pelas vias referidas acima ${ }^{19}$. Um eu que se assume como solidário, caridoso e revoltado, pronto para lutar no sentido de mudar a ordem internacional que está na origem dos flagelos.

A hiperbolização do tema é conseguida pelas estruturas enunciativo-pragmáticas empregues, com particular saliência para o léxico altamente disfórico e os atos expressivos de crítica forte.

Torna-se ainda relevante mencionar a forma sintática de referenciação dos processos, através da passiva de se e da inversão Suj-V ("multiplica-se a degradação social. Acentuam-se as chagas ambientais e agravam-se os problemas dos trabalhadores e alastra a pobreza"), dando focalização aos processos e não aos agentes/objetos. Esta estratégia permite atribuir todos os estados de coisas descritos nas proposições (os problemas sociais) a uma mesma causa, mencionada através de grupos nominais de referência genérica e de valor ideológico: "o domínio absoluto dos grandes grupos económicos" e a "despótica lógica dos mercados", aqueles que são os verdadeiros inimigos a abater. A

${ }^{19}$ Reportamo-nos aqui a um sentido linguístico de subjetividade, entendida como a presença do enunciador no seu enunciado, tal como defendido por autores como Benveniste (1966) e Kerbrat-Orecchioni (1980). 
retórica deste discurso coloca assim a tónica na disputa entre o povo, vítima dos flagelos sociais enumerados, e as elites poderosas, identificadas com os grandes grupos económicos e o mercado.

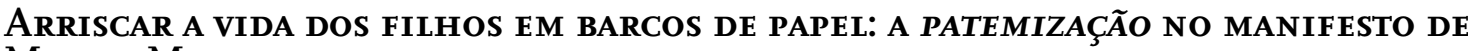 Marisa Matias}

Marisa Matias, doutorada em Sociologia e deputada europeia pelo partido político Bloco de Esquerda, foi a candidata à presidência da república das eleições de 2016 em Portugal que mais espaço dedicou no seu manifesto à questão dos refugiados.

Com um manifesto igualmente prototípico, do ponto de vista retórico e enunciativo-pragmático, verifica-se em Marisa Matias um forte recurso à crítica, evidenciada por mecanismos linguísticos tais como o léxico, selecionado para conferir atributos disfóricos às entidades visadas, e ainda as metáforas e os paralelismos sintáticos. Em termos pragmáticos, coexistem vários atos linguísticos, que servem os principais eixos do texto: a expressão do descontentamento com a situação presente; a crítica e desqualificação do outro, identificado como o responsável pela mesma; a sugestão de mudanças para o futuro; o compromisso de atuação por parte do candidato e o apelo à adesão do tu. Os segmentos abaixo ilustram esta variedade.

Começando pelos atos declarativos de afirmação da candidatura, podemos confrontar os seguintes enunciados: "candidato-me para trazer uma alternativa popular para estas eleições, na convicção de que, numa República, são os votos que decidem quem é que vai estar na chefia do Estado. (...) Candidato-me para ajudar a derrotar este projecto das elites" (Manifesto MM).

Também os atos compromissivos marcam presença, como seria de esperar: "num mundo cheio de injustiça e de guerras, comigo ninguém duvida que Portugal estará sempre, sempre ao lado da justiça e da paz" (Manifesto MM).

Os atos expressivos de crítica são muito numerosos e contundentes, por força dos mecanismos linguísticos já referidos acima:

a direita anda desesperada como nunca a tínhamos visto, os grandes interesses consideram-se em risco e, em conjunto têm um projecto: onde cresce a esperança, espalham o medo; onde se forma a união, semeiam a chantagem; onde há sinais de mudança, tentam manter o status quo. (...) A direita apresenta-se com um rosto mais civilizado, com um ar mais moderno e tolerante, mas não se iludam: quem procurou fazer da televisão um trampolim ao serviço da sua desmesurada ambição política, estará disposto a vender tudo e o seu contrário para atingir os seus objectivos. ${ }^{20}$ (Manifesto MM)

Os atos diretivos são também frequentes, marcando sequências de interpelação direta do tu. Em muitos segmentos, esta interpelação é feita através da construção, já

\footnotetext{
${ }^{20}$ Seria relevante verificar, nestes excertos, de que forma os objetos do discurso são referenciados linguisticamente e quais são as caraterísticas e as qualidades que lhes são atribuídas. A utilização do nome "Direita" é um dos casos interessantes a ressaltar. Não poderemos, todavia, seguir esta pista de análise na medida em que se encontra fora do escopo mais restrito do presente trabalho.
} 
descrita acima, não podemos $x$, que funciona como um complexo ilocutório expressivo de crítica e diretivo de apelo, no qual as repetições lexicais e sintáticas elevam a força ilocutória do ato.

Num Palácio de Belém que cheira a bafio vai ser preciso abrir as janelas para entrar ar fresco. É a força da democracia que as vai abrir. É a vossa força. (...) Não podemos ter um Presidente indiferente à destruição dos direitos constitucionais dos trabalhadores. (...) Não podemos ter um presidente indiferente à pobreza e ao desemprego. (...) Não podemos ter um Presidente indiferente à destruição da nossa agricultura e das nossas pescas em nome do direito à concorrência das multinacionais. ${ }^{21}$ (Manifesto MM)

De todos os manifestos estudados, o manifesto de Marisa Matias é o mais forte em termos da força ilocutória dos atos linguísticos utilizados: as promessas são arrojadas; os atos expressivos de crítica são contundentes; os restantes atos expressivos, em que o locutor exprime o seu estado psicológico sobre o conteúdo proposicional descrito, são atos fortes, com a mobilização de emoções tais como repugnância, solidariedade profunda, afeto, entre outras.

No que diz respeito à sequência dedicada ao tema dos refugiados, este manifesto não foge a esta regra e encerra a sequência mais forte de todas as sequências até aqui analisadas, como podemos comprovar pela leitura do excerto abaixo:

a indiferença das instituições portuguesas face ao drama escandaloso dos refugiados só é compreensível porque temos governantes e representantes que nunca se deram ao trabalho de ir directamente aos locais e falar directamente com quem sofre e conhecer que razões tão profundas tem alguém para decidir abandonar a sua terra, de se fazer ao mar e atravessar a Europa a pé, a empurrar a cadeira de rodas da sua mãe ou a trazer um bebé recém-nascido sujeito às intempéries e ao risco. Nenhuma mãe ou nenhum pai arrisca a vida dos seus filhos em barcos de papel se esses barcos não forem mais seguros que o chão que pisavam antes. Quem não conseguir compreender isto não é digno de ocupar a Presidência da República Portuguesa. (Manifesto MM)

No discurso de Marisa Matias, a situação dos refugiados é alvo de uma dramatização, no sentido que lhe confere Trčková (2014, p. 87) de "uma adoção de temas e esquemas míticos em narrativas sobre vítimas, uma seleção de histórias de vítimas carregadas de emoções". De facto, esta candidata representa a situação de forma altamente avaliativa, facto comprovado pela expressão "drama escandaloso dos refugiados", mostrando, através da referenciação do objeto pelo nome "drama", e da sua qualificação, através do adjetivo avaliativo "escandaloso", a sua conceptualização pessoal da situação. Para

${ }^{21}$ Salientamos o que referimos acima sobre o caráter híbrido destes atos de expressão da modalidade deôntica sob a forma de não podemos $x$, que já analisamos no caso dos outros três manifestos em estudo, excetuando o manifesto de Marcelo Rebelo de Sousa. Trata-se de complexos ilocutórios, que concentram dois valores associados, neste caso, o valor da recomendação e o valor da crítica. 
além desta conceptualização axiologicamente marcada do real, a candidata também particulariza, na sua argumentação, atores e situações específicas vividas nestes dramas, quase construindo narrativas de vida e imagens visuais das mesmas, com as quais o público se pode identificar mais facilmente. Trata-se do recurso a uma estratégia populista de aproximação do tu através da exploração do pathos.

Assim é que a candidata fala de alguém que decide abandonar a sua terra, de se fazer ao mar e atravessar a Europa a pé, a empurrar a cadeira de rodas da sua mãe ou a trazer um bebé recém-nascido, sujeito às intempéries e ao risco. $O$ efeito de contraste entre a fragilidade dos atores sociais trazidos para a cena (a mãe na cadeira de rodas e o bebé recém-nascido) e o caráter violento dos processos a que são sujeitos (abandonar a sua terra; fazer-se ao mar; atravessar a Europa a pé; sujeitar-se às intempéries e ao risco; arriscar a vida) acentua o caráter dramático destas mininarrativas encaixadas em sequências de argumentação. Tal como indica Trčková:

os contrastes são geralmente baseados em oposições binárias (as luzes ténues no bairro normalmente efervescente; subir a colina nestes dias sombrios é mover-se entre a vida e a morte, a tristeza e a esperança; o paraíso rapidamente se torna numa provação), que são ferramentas rudimentares nos sistemas conceptuais dos indivíduos, ajudando-os a impor categorias claras à realidade, mas também simplificando-a e esquematizando-a. (Trčková, 2014, p. 88).

$\mathrm{Na}$ passagem do manifesto de Marisa Matias sobre os refugiados é de salientar ainda o recurso à metáfora dos "barcos de papel" que acentua, pela exploração do traço de fragilidade das vítimas, a carga emocional destas sequências híbridas entre os protótipos narrativo e argumentativo. De facto, trabalhadas como tipos sociais, as personagens destas mininarrativas pretendem simbolizar milhares de pessoas autênticas que experimentam estas mesmas situações, elas mesmas reduzidas a esquemas de ação tipificados e simbólicos (abandonar a sua terra; fazer-se ao mar; atravessar a Europa a pé; sujeito às intempéries e ao risco; arriscar a vida). Por via destes recursos discursivos de dramatização, torna-se claro que a candidata opta por uma forma mais emocional (patémica) de construir empatia com o tu. Estas sequências acumulam, pela estratégia da dramatização, um valor ilocutório derivado de censura às forças políticas oponentes e aos candidatos que as representam, identificados como os responsáveis pelo drama, facto que fica explícito no enunciado que encerra esta sequência, em que a candidata remata, num tom profundamente judicativo: "quem não conseguir compreender isto não é digno de ocupar a Presidência da República Portuguesa".

Esta sequência encerra com a formulação de um discurso de exclusão, onde se separa o eu e o nós, os que compreendem e se preocupam com a situação (grupo em que a candidata se integra), dos outros, que não compreendem a situação, que eventualmente nem lhe dão voz e a quem falta a qualidade essencial da empatia e da solidariedade, não sendo, por isso, dignos de ocupar o cargo da presidência portuguesa. O fecho desta sequência argumentativa configura, desta forma, um ethos autoritário, investido de um 
poder moral suficientemente forte e convicto para formular enunciados judicativos, de valor deôntico alto.

\section{Conclusão}

Retomando a ideia aristotélica de que o ethos é construído no e pelo discurso, Maingueneau $(2005,2008)$ lembra que não existe um ethos preestabelecido, mas, sim, que este se vai construindo durante e a partir da atividade discursiva. Também Giddens (1991, p. 54) salienta a importância da "narrativa de si" na construção de uma identidade pessoal e social:

a identidade de uma pessoa não pode ser encontrada no comportamento, nem - por mais importante que estas sejam - nas reações dos outros, mas sim na capacidade de manter uma narrativa específica em andamento. A biografia da pessoa, se ela deseja manter uma interação regular com outras pessoas no mundo quotidiano, (...) deve integrar continuamente eventos que ocorrem no mundo externo e encaixá-los na «história» em andamento sobre si mesmo. (Giddens, 1991, p. 54)

A construção de um ethos credível por parte dos candidatos políticos é uma das estratégias mais importantes no projeto de conquista do poder. Pudemos verificar, a partir da breve análise comparativa dos manifestos políticos de quatro candidatos presidenciais às eleições portuguesas de 2016, que o estilo de fazer política difere substancialmente entre os candidatos. Os processos semânticos, pragmáticos e discursivos estudados, parecem contribuir, de forma integrada, para a construção das estratégias de silenciamento ou referenciação direta do tema em análise e das consequentes estratégias políticas de conquista do poder. Uma construção retórica forte, com um léxico de polaridade semântica negativa alta e paralelismos recorrentes, encontrada, por exemplo, nos manifestos de Edgar Silva e de Marisa Matias, configura textos em que os atos ilocutórios expressivos de lamento, crítica e denúncia e a correlativa modalidade apreciativa ganham particular relevo, servindo a construção clara de projetos políticos de "oposição". Já nos manifestos dos outros dois candidatos analisados, a moderação das propostas políticas encontra reflexo numa igualmente moderada seleção do léxico, dos atos linguísticos e das estratégias de modalização.

Assim, confirma-se que o tratamento da crise dos refugiados nos manifestos eleitorais presidenciais de cada um reflete e contribui para a construção dos ethè e das estratégias políticas respetivas. Os dois candidatos mais moderados do leque dos mais votados - Marcelo Rebelo de Sousa e António Sampaio da Nóvoa - optaram por não referenciar diretamente a questão dos refugiados nos seus manifestos, dando-lhe voz de uma forma mais genérica através da referência à questão da emigração e à questão da integração de Portugal na Europa e da perda de ideais da Europa. Silenciar também é uma estratégia, sendo que uma das conclusões que podemos tirar é a de que optar por não nomear e não assumir uma posição direta sobre este assunto fraturante é uma posição política prudente, para quem almeja um eleitorado mais abrangente em termos 
de cor política e para quem quer construir um ethos politicamente menos marcado. Comprovamos, igualmente, pela leitura dos excertos alusivos destes manifestos, que Marcelo Rebelo de Sousa é o que aborda a questão de forma mais empática e afetiva, apresentando-se, ele mesmo, como um emigrante. Elimina, desta forma, as distâncias potencialmente existentes entre ele mesmo, locutor; o objeto de discurso representado (os emigrantes, os refugiados) e o tu. Concretiza, assim, uma estratégia ambígua, que Ihe permite referir a questão sem tomar posição política sobre a mesma.

Em contrapartida, os dois candidatos posicionados mais à esquerda representam e avaliam o problema dos refugiados de forma marcada, no contexto de uma construção ideológica que opõe um eu/nós a um outro/outros, dignos de crítica e despromoção, contribuindo assim para a construção de uma estratégia política e de um ethos de oposição e de combate social. Confirmamos, também, a partir da análise dos manifestos, que a exploração do pathos, através do aumento do tom subjetivista e dramático nas macroestruturas dedicadas ao tema, denuncia o aproveitamento populista do mesmo. Nestes manifestos a vitimização dos refugiados, tratados como personagens-tipo "redondas" que representam milhares de pessoas reais e a esquematização (simplificação) das situações vividas por eles, sempre por recurso a um léxico disfórico forte, marca uma estratégia de ativação de emoções no eleitorado que passam pela simpatia, pela revolta, pela indignação e, consequentemente, pela vontade de mudança.

\section{REFERÊNCIAS}

Adam, J. M. (2001). En finir avec les types de textes. In M. Ballabriga (Ed.), Analyse des discours. Types et genres: communication et interprétation (pp. 25-43). Toulouse: EUS.

Adam, J. M. (2008). A Linguística textual: uma introdução à análise textual dos discursos. São Paulo: Contexto.

Benveniste, É. (1966). De la subjectivité dans le langage. In Problèmes de linguistique générale I (pp. 258-266). Paris: Gallimard.

Campos, M. H. C \& Xavier, M. F. (1991). Sintaxe e semântica do Português (pp. 361-379). Lisboa: Universidade Aberta. Retirado de https://area.dge.mec.pt/gramatica/umfimtriste/valoresmodaisio.html\#topo

Campos, M. H. C. (2004). A modalidade apreciativa: uma questão teórica. In F. Oliveira \& I. M. Duarte (Eds.), Da língua e do discurso (pp. 265-281). Porto: Campo das Letras.

EsquerdaNet. (2015). Marisa Matias / Apresentação da candidatura à Presidência da República 2016. Retirado de https://www.youtube.com/watch?v=idiwx4L3xsk\&index=40\&list=PLYhag9yGog27Hnez8eQ6rt3Uef8iel Egg

Giddens, A. (1991). Modernity and self-identity: self and society in the late modern age. Cambridge: Polity.

Kerbrat-Orecchioni, C. (1980). L'énonciation de la subjectivité dans le langage. Paris: Armand Colin.

Maingueneau, D. (2005). Ethos, cenografia, incorporação. In R. Amossy (Ed.), Imagens de si no discurso: a construção do ethos (pp. 69-92). São Paulo: Contexto.

Maingueneau, D. (2008). A propósito do ethos. In A. R. Motta \& L. S. Salgado (Eds.), Ethos discursivo (pp. 11-29). São Paulo: Contexto. 
Oliveira, F. (2003). Modalidade e modo. In M. H. M. Mateus; A. M. Brito; I. Duarte \& I. H. Faria (Eds.), Gramática da Língua Portuguesa (pp. 245-247). Lisboa: Caminho.

Oliveira, F. \& Mendes, A. (2013). Modalidade. In E. P. Raposo; M. F. B. Nascimento; M. A. Mota; L. Segura \& A. Mendes (Eds.), Gramática do Português (vol. I.) (pp. 623-669). Lisboa: Edição Fundação Calouste Gulbenkian.

Pinto, A. (2012). Dialogismo, polifonia e heterogeneidade enunciativa nos manifestos políticos das presidenciais de 2011. Estudos Linguísticos/Linguistic Studies, 8, 195-212. Retirado de https://clunl.fcsh. unl.pt/wp-content/uploads/sites/12/2018/02/195_212.pdf

Pinto, A. G., Pinho, A. C. \& Teixeira, J. (2017). Polarização e construção da força discursiva em manifestos políticos: o caso das presidenciais portuguesas de 2016. Linha D’Água, 30(1), 35-68. Retirado de http:// www.revistas.usp.br/linhadagua/article/view/133203

Searle, J. (1969). Speech acts. An essay in the philosophy of language. Cambridge: Cambridge University Press.

Trčková, D. (2014). Representations of natural catastrophes in newspaper discourse. Brno: Masarykova univerzita. Retirado de https://digilib.phil.muni.cz/handle/11222.digilib/133015

Wodak, R. (2001). The discourse historical approach. In R. Wodak \& M. Meyer (Eds.), Methods of critical discourse analysis (pp. 63-94). Londres: Sage.

\section{NOTA BIOGRÁFICA}

Alexandra Guedes Pinto, doutorada em Linguística e Professora Associada do Departamento de Estudos Portugueses e Estudos Românicos, da Faculdade de Letras da Universidade do Porto (FLUP). Membro do Conselho Científico do Centro de Linguística da Universidade do Porto e da Comissão Científica do Mestrado em Tradução e Serviços Linguísticos da FLUP. Membro da Comissão Científica do IJUP - Investigação Jovem da Universidade do Porto (UP). Membro do grupo de trabalho de publicidade da Sopcom e do grupo "Argumentation Hub" dos Laboratórios MIL da UP. Participante em vários projetos e redes de investigação internacionais. Organizadora, desde 2011, das "Jornadas Internacionais de Análise do Discurso - JADIS" (http://web4.letras.up.pt/jadis) e fundadora e responsável editorial da revista REDIS - Revista de Estudos do Discurso (http://ojs. letras.up.pt/index.php/re). Autora de várias publicações na área dos Estudos do Discurso, consultáveis em https://www.cienciavitae.pt/CB1D-AA66-6572.

ORCID: http://orcid.org/oooo-0001-9120-1542

Email:mapinto@letras.up.pt

Morada: Rua Senhora da Penha, $n^{\circ} 250,4460-423$, Sra. da Hora, Portugal

\section{Submetido: $14 / 04 / 2020$}

Aceite: $01 / 07 / 2020$ 